University of Wollongong

Research Online

Faculty of Engineering and Information

Faculty of Engineering and Information

Sciences - Papers: Part A

Sciences

$1-1-2013$

\title{
Multi-factor coupling system characteristic of the dynamic roll gap in the high-speed rolling mill during the unsteady lubrication process
}

Qiaoyi Wang

General Research Institute for Non Ferrous Metals, Hangzhou Dianzi University

Zhengyi Jiang

University of Wollongong, jiang@uow.edu.au

Jingwei Zhao

University of Wollongong, jzhao@uow.edu.au

Min Fang

Hangzhou Dianzi University

Follow this and additional works at: https://ro.uow.edu.au/eispapers

Part of the Engineering Commons, and the Science and Technology Studies Commons

Research Online is the open access institutional repository for the University of Wollongong. For further information contact the UOW Library: research-pubs@uow.edu.au 


\title{
Multi-factor coupling system characteristic of the dynamic roll gap in the high- speed rolling mill during the unsteady lubrication process
}

\author{
Abstract \\ In the present work, a multi-factor coupling dynamic model of a rolling mill system for a dynamic roll gap \\ during an unsteady lubrication process was developed on the basis of the rolling theory, lubrication and \\ the friction theory, and the mechanical vibration theory. The multi-factor coupling model of interfacial film \\ binding was coupled with the rolling force model, dynamic roll gap interface friction model and work roll \\ movement model. The corresponding distributions of friction and pressure at varying surface roughness \\ and times were systematically analyzed during the unsteady mixed lubrication process. The effects of the \\ main processing parameters on the critical speed and amplitude for self-excited vertical vibration were \\ investigated.
}

\section{Keywords}

during, unsteady, lubrication, process, coupling, system, characteristic, dynamic, multi, roll, factor, gap, high, speed, rolling, mill

\section{Disciplines \\ Engineering | Science and Technology Studies}

\section{Publication Details}

Wang, Q., Jiang, Z., Zhao, J. \& Fang, M. (2013). Multi-factor coupling system characteristic of the dynamic roll gap in the high-speed rolling mill during the unsteady lubrication process. Tribology International, 67 174-181. 


\title{
Multi-factor coupling system characteristic of the dynamic roll gap in the high-speed rolling mill during the unsteady lubrication process
}

\author{
Qiaoyi Wang ${ }^{1}$, Zhengyi Jiang, ${ }^{2, *}$ Jingwei Zhao ${ }^{2}$, Min Fang ${ }^{1}$ \\ ${ }^{1}$ School of Mechanical Engineering, Hangzhou Dianzi University, Hangzhou, Zhejiang 310018, P.R. China \\ ${ }^{2}$ School of Mechanical, Materials and Mechatronic Engineering, University of Wollongong, NSW 2522, \\ Australia
}

\begin{abstract}
In the present work, a multi-factor coupling dynamic model of a rolling mill system for a dynamic roll gap during an unsteady lubrication process was developed on the basis of rolling theory, lubrication and friction theory, and mechanical vibration theory. The multi-factor coupling model of interfacial film binding was coupled with the rolling force model, dynamic roll gap interface friction model and work roll movement model. The corresponding distributions of friction and pressure at varying surface roughness and times were systematically analyzed during the unsteady mixed lubrication process. The effects of the main processing parameters on the critical speed and amplitude for self-excited vertical vibration were investigated.
\end{abstract}

Keywords: Dynamic roll gap; Multi-factor coupling; Vibration; Interface

*Corresponding author: Tel.:+61-2-42214545; Fax: +61-2-42215474.

E-mail address: jiang@uow.edu.au (Z. Jiang) 


\section{Nomenclature}

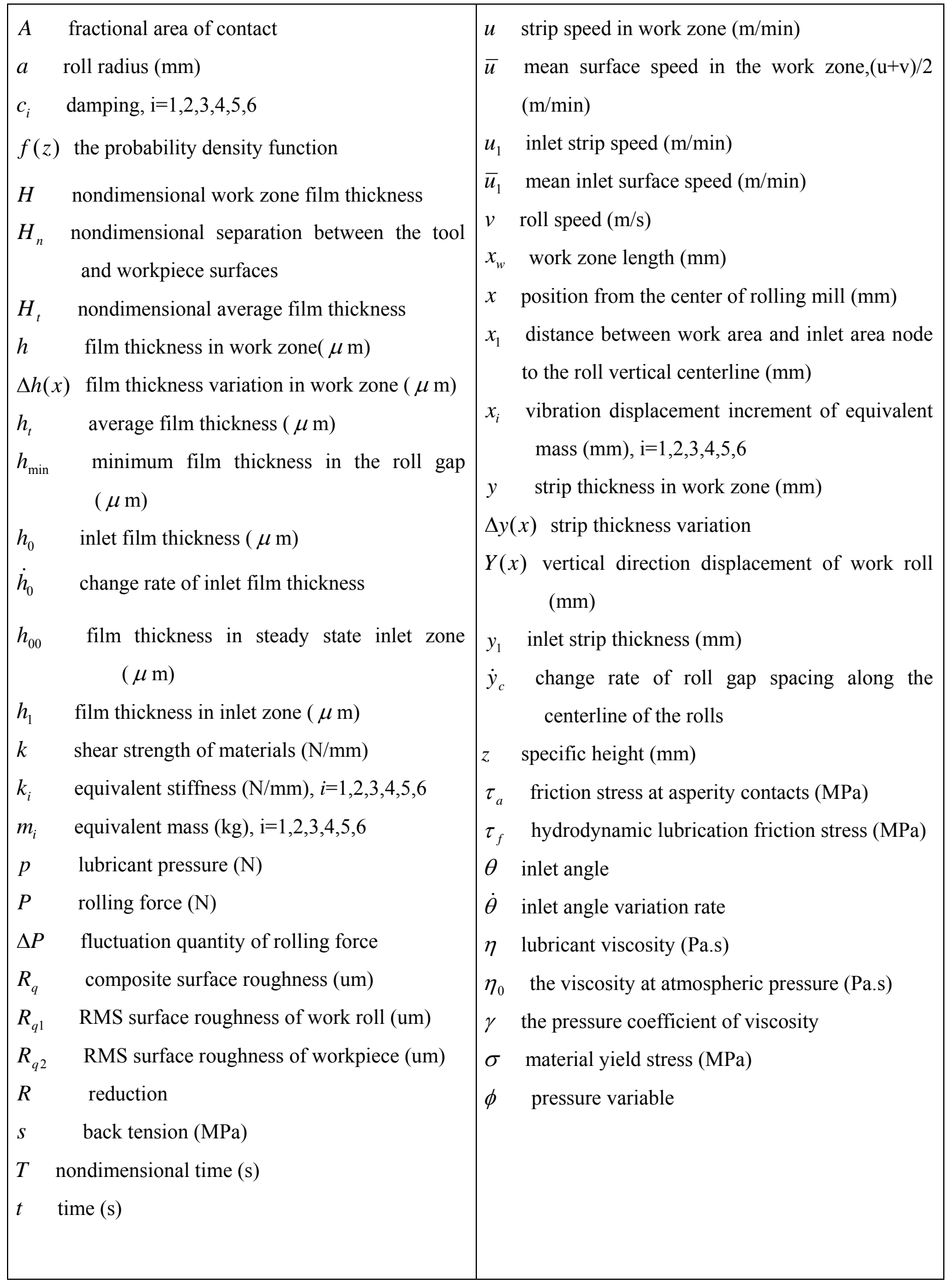




\section{Introduction}

The film thickness and the surface roughness [1] of roll and strip significantly affect the friction and lubrication states of the roll gap in metal rolling. In general, when the ratio of the minimum film thickness $h_{\min }$ to the composite surface roughness $R_{q}\left(R_{q}=\sqrt{R_{q 1}^{2}+R_{q 2}^{2}}\right.$, where $R_{q 1}$ and $R_{q 2}$ are the root mean

square (RMS) surface roughness of roll and strip, respectively) is greater than $3\left(\frac{h_{\min }}{R_{q}}>3\right)$ in the roll gap, the interface is in a hydrodynamic friction and lubrication state. When the ratio is less than 0.5 , however, the state of interface is changed to be boundary friction and lubrication. Otherwise, the interface is in a mixed lubrication state with boundary and hydrodynamic friction and lubrication when the ratio lies between 0.5 and 3 .

In low-speed rolling, the thickness of the roll inlet film is small. Correspondingly, the thickness of lubrication film in the roll gap is small, and the rolling process is usually accompanied by an interface state of boundary friction and lubrication. With increasing rolling speed, the film thickness in the roll gap increases, and the interface state will be changed from a simple boundary friction and lubrication to be a mixed lubrication state. When the speed is high, a pure hydrodynamic friction and lubrication state will occur. Rolling is a transient and time-related $[2,3]$ process. Due to the vibration of the rolling mill structure, a non-steady-state lubrication and friction will be caused during rolling [4-6]. Since the rolling process is one of the most important metal forming processes with large deformations [7, 8], it is of great significance to understand the unsteady lubrication [9-12] phenomenon, and then to build up a more realistic tribological model under a unsteady state process, producing a desirable strategy for vibration avoidance[13, 14]. An accurate dynamic model for the rolling process had been developed based on the understanding of the unsteady lubrication mechanism. Hu $[13,14]$ discarded the assumption of constant strip exit velocity and the use of forward and backward slips in velocity calculations, and therefore allowed the model to be more suitable for 
chatter studies. He also took into account the roll horizontal movement allowing the effects of complicated roll vibrations to be considered. Compared with the model proposed in references 13 and 14, the main feature of the developed model in this paper is that the multi-factor coupling system dynamical model of interfacial film binding is coupled with the rolling force model, dynamic roll gap interface friction model and work roll movement models. The corresponding distributions of friction and pressure at varying surface roughness and times are systematically analyzed during the unsteady mixed lubrication process. The effects of the main processing parameters on the critical speed and amplitude for self-excited vertical vibration are investigated.

During cold unsteady rolling, the friction in the roll gap is generally in a mixed state of lubrication and friction. Therefore, it is of importance to establish a rolling mill system dynamic model of the roll gap by considering the mixed unsteady lubrication. This paper aims to develop a multi-factor coupling dynamic model of a cold rolling mill system for dynamic roll gap at unsteady lubrication processes. The distribution of friction and compressive stresses at different surface roughness and times will be systematically investigated. The effects of some main parameters on the critical speed and amplitude of the mill self-excited vertical vibration will also be analyzed.

\section{Interfacial unsteady lubrication model}

\subsection{Film thickness model of the inlet area}

The geometries of roll bite and inlet zone of a cold rolling system are shown in Figs. 1 and 2, respectively.

The compressive stress distribution of the lubricant can be determined by the Reynolds equation [15]

$$
\bar{u}_{1} \frac{\partial h_{1}}{\partial x}-\frac{\partial h_{1}}{\partial t}+\frac{\partial}{\partial x}\left(\frac{h_{1}^{3}}{12 \eta} \frac{\partial p}{\partial x}\right)=0
$$


where $p$ is the lubricant pressure, $h_{1}$ is the film thickness in inlet zone, $\eta$ is the lubricant viscosity, $t$ is the time, $x$ is the position from the center of rolling mill, and $\bar{u}_{1}$ is the mean inlet surface speed.

The relationship between viscosity $\eta$ and lubricant pressure $p$ can be expressed by the Barus stick pressure formula [16]:

$$
\eta=\eta_{0} e^{i p}
$$

where $\eta_{0}$ is the viscosity at atmospheric pressure, and $\gamma$ is the lubricant viscosity. To simplify the analysis, a dimensionless pressure variable as $\phi$ is introduced in the model:

$$
\phi=e^{-\gamma p}
$$

Assume that the oil film thickness of the rolling mill can be described as a function of location

$$
h_{1}=\theta x+h_{0}
$$

where $h_{0}$ is the inlet film thickness ( including the inlet area and the work area in the intersection of the oil film thickness), and $\theta$ is the inlet angle.

Substituting Eqs. (2) - (4) into Eq. (1):

$$
6 \gamma \eta_{0}\left(2 \theta \bar{u}_{1} \frac{x}{h_{1}^{3}}-2 \dot{h_{0}} \frac{x}{h_{1}^{3}}-\dot{\theta} \frac{x^{2}}{h_{1}^{3}}\right)-\frac{\partial \phi}{\partial x}=0
$$

Based on Eq. (5), the pressure $\phi$ tends to 1 when $h_{1}$ and $x$ tend to infinity. When the boundary condition satisfies the relations of $h_{1}=\infty$ and $x=\infty, \quad \phi$ becomes a constant of 1 . Then, the pressure $\phi$ can be expressed as:

$$
\phi=-6 \gamma \eta_{0} \dot{\theta}\left\{\frac{4 a^{3}\left[\left(a \theta^{2}-2 h_{0}\right) x+h_{0}(x+a \theta)\right]}{\left(a \theta^{2}-2 h_{0}\right)\left(2 a h_{0}+2 a \theta x+x^{2}\right)}+\frac{2 a^{2}\left(h_{0}+a \theta^{2}\right)(x+a \theta)}{\left(a \theta^{2}-2 h_{0}\right)^{2}\left(2 a h_{0}+2 a \theta x+x^{2}\right)}\right.
$$




$$
\begin{aligned}
& \left.+\frac{a^{2}\left(h_{0}+a \theta^{2}\right)}{\left(a \theta^{2}-2 h_{0}\right)^{2} \sqrt{a\left(a \theta^{2}-2 h_{0}\right)}} \ln \left(\frac{x+a \theta-\sqrt{a\left(a \theta^{2}-2 h_{0}\right)}}{x+a \theta+\sqrt{a\left(a \theta^{2}-2 h_{0}\right)}}\right)\right\} \\
& +\frac{12 \gamma \eta_{0}}{\theta}\left(\bar{u}_{1}-\frac{\dot{h}_{0}}{\theta}\right)\left(-\frac{1}{h_{1}}+\frac{h_{0}}{2 h_{1}^{2}}\right)+1
\end{aligned}
$$

where $a$ is the roll radius. At the inlet edge of the roll bite zone, $h_{1}=h_{0}, x=0$. The pressure $\phi$ can then be solved by applying the Tresca yield criterion [17]:

$$
p=\sigma-s
$$

where $\sigma$ is the material yield stress, and $s$ is the back tension. The simplified dimensionless pressure $\phi$ becomes:

$$
\phi=e^{-\gamma(\sigma-s)}
$$

At the inlet edge of the roll bite, $h_{1}=h_{0}, x=0$ Substituting Eq. (8) into Eq. (6), it then becomes:

$$
\frac{6 \gamma \eta_{0}}{\theta h_{0}}\left(\bar{u}_{1}-\frac{\dot{h_{0}}}{\theta}\right)+6 \gamma \eta_{0} \dot{\theta} C_{R}+e^{-\gamma(\sigma-s)}-1=0
$$

where $C_{R}$ is expressed as:

$$
C_{R}=\frac{a^{2} \theta\left(2 a \theta^{2}-h_{0}\right)}{h_{0}\left(a \theta^{2}-2 h_{0}\right)}+\frac{a^{2}\left(a \theta^{2}+h_{0}\right)}{\left(a \theta^{2}-2 h_{0}\right)^{2} \sqrt{a\left(a \theta^{2}-2 h_{0}\right)}} \ln \left[\frac{a \theta-\sqrt{a\left(a \theta^{2}-2 h_{0}\right)}}{\left.a \theta+\sqrt{a\left(a \theta^{2}-2 h_{0}\right.}\right)}\right]
$$

Based on Eq. (9), the rate of change of inlet film thickness can be solved by:

$$
\dot{h_{0}}=\theta^{2} h_{0} \dot{\theta} C_{R}-\frac{\theta^{2} h_{0}\left(1-e^{-\gamma(\sigma-s)}\right)}{6 \gamma \eta_{0}}+\theta \bar{u}_{1}
$$

According to Eq. (11), the rate of change of film thickness is closely related to the back tension $s$, mean inlet surface speed $\bar{u}_{1}$, inlet angle $\theta$, and inlet angle variation rate $\dot{\theta}$.

\subsection{Roll bite film thickness model}


Strip speed changes along the direction of horizontal $X$. Yun [18] proposed the continuity equation of the roll bite as follows:

$$
\left(x_{w}-x\right) \dot{y}_{c}-u_{1} y_{1}+u y=0
$$

where $\dot{y}_{c}$ is the change rate of roll gap spacing along the centerline of the rolls, and $x_{w}$ is the distance between work area and inlet area node to the roll vertical centerline. The roll bite strip thickness $y$ can be determined by the following equation [19]

$$
y=\frac{x^{2}}{a}+y_{1}(1-R)
$$

where $R$ is the reduction, $y_{1}$ is the inlet strip thickness, and $a$ is the roll radius.

Because the gradient of roll bite pressure is much smaller than that of the inlet pressure, the pressure gradient that in the Reynolds equation can be ignored. Therefore, Eq. (1) can be rewritten as:

$$
\bar{u} \frac{\partial h}{\partial x}-\frac{\partial h}{\partial t}+\frac{\partial \bar{u}}{\partial x}=0
$$

where $\bar{u}$ is the mean surface speed in the work zone, and $h$ is the film thickness in work zone. Eq. (14) is a first-order partial differential equation, which can be solved by using a mathematical method. The roll bite film thickness $h$ can be expressed as a function of the inlet film thickness $h_{0}$ as follows:

$$
h=\frac{v+u_{1}}{v+u(x)} h_{0}
$$

where $h_{0}$ is the inlet film thickness, $u_{1}$ is the inlet strip speed, $u(x)$ is the strip speed in work zone, and $v$ is the roll speed. The roll bite film thickness $h$ can be determined by using the above developed models.

\subsection{Interfacial friction model}

The surface roughness of the work roll and the strip is uneven. Gauss [20] distribution of the surface roughness is generally assumed along the height direction, by which the real contact surface area ratio can be 
estimated. According to the adhesion friction theory [21], the rough contact surface boundary lubrication and frictional stress $\tau_{a}$ can be calculated by:

$$
\tau_{a}=k
$$

where $k$ is shear strength of materials. Hydrodynamic lubrication and friction generated by the lubrication shear stress can be obtained as:

$$
\tau_{f}=\eta \frac{(u-v)}{h}
$$

where $\eta$ is the lubricant viscosity, $u$ is the strip speed in work zone, $v$ is the roll speed, and $h$ is the gap between the surfaces of the strip and roll. In the mixed lubrication state, the load and friction of the joint surface are partly held by the rough contact surface, and the other part is held by the pressure lubricating oil in the groove on the contact surface. In the mixed lubrication, the typical expression of the total frictional stress is

$$
\tau=A \tau_{a}+(1-A) \tau_{f}
$$

where $A$ is fractional area of contact, which is actually the contact area ration of rough micro peak in the roll gap, $\tau_{a}$ and $\tau_{f}$ are friction stress at asperity contacts and hydrodynamic lubrication friction stress, respectively. The true contact area ratio A plays an important role in the mixed lubrication state for the frictional stress.

\subsection{The real contact area ratio of random rough surface}

The work of Christensen [22] showed that the probability density function of the specific height can be determined by:

$$
\begin{aligned}
f(z) & =\frac{35}{96 R_{q}}\left[1-\frac{1}{9}\left(\frac{z}{R_{q}}\right)^{2}\right]^{3} & & \text { when }|z| \leq 3 R_{q} \\
& =0 & & \text { when } z>3 R_{q}
\end{aligned}
$$


where $z$ is the specific height, $R_{q}$ is the composite surface roughness. Christensen's contact diagram of the surface roughness is schematically illustrated in Fig. 3. According to Fig. 3, the distribution probability density of the roughness can be expressed as:

$$
h_{t}=\int_{-h}^{\infty}(h+z) f(z) d z
$$

Making $h$ and $h_{t}$ in Eq. (20) dimensionless, the result is as follows:

$$
\begin{gathered}
Z=\frac{h}{3 R_{q}} \\
H_{t}=\frac{h_{t}}{R_{q}}
\end{gathered}
$$

Subsituting Eq. (19) into Eq. (20), it becomes that:

$$
H_{t}=3\left\{35+Z\left[128+Z\left(140+Z^{2}\left(-70+Z^{2}\left(28-5 Z^{2}\right)\right)\right)\right]\right\} / 256
$$

The real contact area ration at a particular height $h$ can be obtained through the probability density function integral:

$$
A=\int_{h}^{\infty} f(z) d z
$$

Applying dimensionless form:

$$
A=\left(16-5 Z+35 Z^{3}-21 Z^{5}+5 Z^{7}\right) / 32
$$

The real contact area ration $A$ can be expressed in the form of nondimensional average film thickness $H_{t}$. As a result, the following relationship can be obtained by Eqs. (23) and (25). 


$$
\begin{aligned}
A= & 1, H_{t}\langle 0.5 \\
A= & 1.0-2.4398 H_{t}+6.2049 H_{t}^{2}-11.8410 H_{t}^{3}+12.5350 H_{t}^{4} \\
& -6.6134 H_{t}^{5}+1.3618 H_{t}^{6}, 0.5\left\langle H_{t} \leq 1.5\right. \\
A= & 0.8855-1.1982 H_{t}+0.7614 H_{t}^{2}-0.3394 H_{t}^{3}+0.1116 H_{t}^{4} \\
& -0.0220 H_{t}^{5}+0.0018 H_{t}^{6} 1.5\left\langle H_{t} \leq 3.0\right. \\
A= & \left.0, H_{t}\right\rangle 3.0
\end{aligned}
$$

When the ratio is less than 0.5 , however, the state of the interface is changed to be boundary friction and lubrication. Otherwise the interface is in a mixed lubrication state with boundary and hydrodynamic friction and lubrication when the ratio lies between 0.5 and 3 .

\section{Dynamic roll gap work rolling motion analysis}

Work roll movement is related to the opening degree of the roll gap, the strip thickness and the extrusion speed of the interfacial oil film, which can be expressed by the following relationships:

$$
\begin{aligned}
& Y(x)=\frac{1}{2} \cdot \Delta y(x)+\Delta h(x) \\
& \dot{Y}(x)=\frac{1}{2} \cdot \Delta \dot{y}(x)+\Delta \dot{h}(x)
\end{aligned}
$$

where $Y(x)$ is the vertical direction displacement of work roll, $\Delta y(x)$ is the strip thickness variation, and

$\Delta h(x)$ is the film thickness variation in work zone. When the deformation zone is in a state of mixed lubrication and dry friction (asperity height being greater than the thickness of the oil film), Eqs. (27) and (28) can be expressed as:

$$
\begin{aligned}
& Y(x)=\frac{1}{2} \cdot \Delta y(x) \\
& \dot{Y}(x)=\frac{1}{2} \cdot \Delta \dot{y}(x)
\end{aligned}
$$

At the inlet area, where the incoming thickness is assumed to be a constant, and then:

$$
\dot{Y}(x)=\dot{h}_{1}(x)
$$




\section{The friction and compressive stress distributions in the dynamic roll gap}

When the oil film in the deformation area is less than 3 times RMS surface roughness, the friction and compressive stress should be calculated according to the mixed lubrication state. The oil film thickness distribution $H_{n}$ at a particular time under the full-film lubrication state is obtained by:

$$
\begin{gathered}
H_{n}<3 \\
H_{n}=\frac{h}{R_{q}}=\frac{H \cdot h_{00}}{R_{q}}
\end{gathered}
$$

where $H$ is the nondimensional work zone film thickness, and $h_{00}$ is the film thickness in steady state inlet zone [7]. In the mixed lubrication state, the average film thickness $H_{t}$ can be calculated by the full-film lubrication theory

$$
H_{t}(x, T)=H_{n}(x, T)
$$

where $T$ is the nondimensional time.

Fig. 4 shows a micro-unit body of the strip. The force balance equation in the $X$-direction can be obtained by ignoring a relatively small item:

$$
s \frac{d y}{d x}+y \frac{d s}{d x}+p \frac{d y}{d x}+2 \tau_{f}=0
$$

where $s$ is the strip tension stress, $y$ is the strip thickness in local point, $p$ is the local stress, and $\tau_{f}$ is the local friction stress.

The deformation area balance equation can be obtained using the plastic flow yield criterion [19] as follows:

$$
\sigma \frac{d y}{d x}-y \frac{d p}{d x}+2 \tau_{f}=0
$$


The frictional stress term $\tau_{f}$ is generated by the viscous shear of the lubricant film, which can be obtained by Eq. (17). Compressive stress and frictional stress distributions of the strip rolling process can be solved by calculating Eqs. (17) and (36).

Then, a developed film model of the interface can be obtained by considering the influence factors including rolling force, interfacial friction and work roll motion of the deformation constitute. The interfacial coupling relationship diagram is shown in Fig. 5.

\section{Mathematical model of the vertical vibration rolling mill in the unsteady lubrication process}

According to the characteristics of a 2800 rolling mill in a large iron and steel plant, the system can be divided into six degrees of freedom in the vibration system so that there are six qualities and seven springs.

Fig. 6 shows a simplified vertical vibration model of the 2800 rolling mill system. Mass $\mathrm{m}_{1} \sim \mathrm{m}_{6}$ represents the equivalent mass of the upper mill, the rack uprights of the rolling mill, the upper backup roll and its bearing and bearing seat, the upper work roll, the lower work roll, the lower backup roll and its bearing and bearing seat, and the rack lower beam. Stiffness $\mathrm{k}_{1}$ is the equivalent stiffness of rack column and the upper beam; $k_{2}$ is the equivalent stiffness from the middle of the upper backup roll to the middle of the upper beam; $\mathrm{k}_{3}$ is to the elastic contact stiffness between the upper work roll and the upper backup roll; $\mathrm{k}_{4}$ is the equivalent stiffness between the upper/lower work rolls and the strip under the rolling force $P$; $\mathrm{k}_{5}$ is the elastic contact stiffness between the lower work roll and the lower backup roll; $\mathrm{k}_{6}$ is the equivalent stiffness from the middle of the lower backup roll to the middle of the lower beam; and $\mathrm{k}_{7}$ is the bending equivalent stiffness of the lower beam. Displacement $\{x\}$ is the vibration displacement increment of the various 
qualities. In the model, the damping $c_{1}$ caused by the pressure cylinder above the upper backup roll, and the damping $c_{2}$ caused by the strip between the two work rolls are considered.

The mathematical model of the rolling mill system with vertical vibration can be obtained as follows:

$$
\begin{aligned}
& m_{1} \ddot{x}_{1}+c_{1}\left(\dot{x}_{1}-\dot{x}_{2}\right)+\left(k_{1}+k_{2}\right) x_{1}-k_{2} x_{2}=0 \\
& m_{2} \ddot{x}_{2}+c_{1}\left(\dot{x}_{2}-\dot{x}_{1}\right)-k_{2} x_{1}+\left(k_{2}+k_{3}\right) x_{2}-k_{3} x_{3}=0 \\
& m_{3} \ddot{x}_{3}+c_{2}\left(\dot{x}_{3}-\dot{x}_{4}\right)-k_{3} x_{2}+\left(k_{3}+k_{4}\right) x_{3}-k_{4} x_{4}=\Delta P \\
& m_{4} \ddot{x}_{4}+c_{2}\left(\dot{x}_{4}-\dot{x}_{3}\right)-k_{4} x_{3}+\left(k_{4}+k_{5}\right) x_{4}-k_{5} x_{5}=-\Delta P \\
& m_{5} \ddot{x}_{5}-k_{5} x_{4}+\left(k_{5}+k_{6}\right) x_{2}-k_{6} x_{6}=0 \\
& m_{6} \ddot{x}_{6}-k_{6} x_{5}+\left(k_{6}+k_{7}\right) x_{6}=0
\end{aligned}
$$

Fig. 7 shows the simulation block diagram, which is compiled by using Microsoft Fortran Power Station language. There are two main purposes for the simulation : 1) to quantitatively analyze the main parameters which affect the rolling mill vertical self-excited vibration critical speed and amplitude, and 2) to systematically analyze the frictional and compressive stresses as the roll gap changes with time and surface roughness distribution under unsteady mixed lubrication states.

\section{Results and discussion}

\subsection{Effects of main parameters on rolling mill vertical self-existed vibration critical speed and amplitude}

In view of the 2800 rolling mill vibration problem of a large iron and steel company, a simulation program was used to quantitatively analyse the effects of the main parameters on the vertical self-excited vibration critical speed and amplitude of the rolling mill. The rolling mill system parameters and the parameters of emulsion performance are listed in Table 1. 
Fig. 8 shows the effect of lubricant viscosity on rolling vibration critical speed. It can be seen that the critical speed of the vibration decreases with increasing viscosity. This is because the viscosity of the emulsion increases which causes an increase of emulsion film thickness of the rolling mill inlet area, and resulting in an increase of the film thickness in the roll gap, which decreases the contact area ration in the rough micro-peak roll gap, due to shear stress and friction in the roll gap. As a result, the system stability reduces, causing self-excited vibration.

Figs. 9 and 10 show the effect of strip outlet and inlet thickness on vibration critical speed, respectively. It can be seen that the vibration critical speed decreases with increasing inlet thickness and decreasing outlet thickness, respectively, indicating that self-excited vibration will easily occur. This is because by increasing inlet thickness and reducing the outlet thickness leads to an increase in the reduction of the rolling mill, and consequently an increase in roll force fluctuation quantities. Because of interface negative damping generated by the increase of the inlet tension, vibration will occur in the system.

Fig. 11 shows the effect of the composite surface roughness of strip and roll on system vibration critical speed. As shown in Fig. 11, the vibration critical speed of the rolling mill vertical system shows an increasing trend towards roughness, indicating that the system does not easily experience vibration. With increasing surface roughness, both the contact area ration in the rough micro-peak roll gap and the shear stress of the system will increase, and an improved stability in the system will be obtained.

Fig. 12 shows the effect of work roll radius on vibration critical speed. It can be seen that a decrease in work roll radius induces decreased rolling mill vibration critical speed. With decreasing the work roll radius, the 
contact arc length and the length of the entire working area will decrease, resulting in a decrease in shear stress with more stability within the system expected.

Fig. 13 shows the relationship between the rolling speed and the amplitude of the self-excited vibration. It can be seen that the vibration amplitude increases with increasing rolling speed. Therefore, the deceleration measures must be taken to prevent the self-excited vibration.

Figs.8- 13 show the calculated results obtained by using the multi-factor coupling system dynamic model in the current work. It can be seen that the calculated results are in good agreement with the measurement data. The results indicate that the developed multi-factor coupling system dynamic model of interfacial film binding that was coupled with the rolling force model, dynamic roll gap interface friction model and work roll movement model has significant practical applications.

\subsection{The roll gap frictional stress and compressive stress distribution under unsteady mixed lubrication states}

Figs. 14 and 15 show the distributions of compressive stress and frictional stress in the deformation area at three different moments based on sine back tension input. The mill reduction $R$ is 0.15 . The surface roughness $R_{q}$ is 1 and $6 \mu \mathrm{m}$. The higher surface roughness means that the working area has a larger contact area. The simulation dimensionless angular frequency is $2 \pi$, so the complete cycle of back tension change is between $T=0$ and $T=1$. Therefore, the chosen contrast nondimensional time $T$ is $0.25,0.50$ and 0.75 respectively, and at this time the back tension is at the highest, the average and the lowest value respectively.

Fig. 14 shows that, when the rough surfaces contact, compressive stress is also increased with the increase of

surface roughness. Under the condition of higher back tension $(T=0.25)$, when $R_{q}=6 \mu \mathrm{m}$, the 
compressive stress value in the deformation area is far greater than the value of the compressive stress in the deformation area when $R_{q}=1 \mu \mathrm{m}$. This result indicates that in the case of larger back tension, compressive stress on the surface roughness is very sensitive. However, when the back tension is reduced, the compressive stress on the surface roughness becomes less sensitive. When $T=0.75$, back tension reaches a minimum, where the compressive stress distribution curve coincides at $R_{q}=1 \mu \mathrm{m}$ and $R_{q}=6 \mu \mathrm{m}$.

Fig. 15 indicates that the surface roughness has a significant effect on the distribution of frictional stress in the deformation area. When having larger back tension, the compressive stress in the roll gap is lower (Fig. 14), but the frictional stress distribution is very sensitive to the surface roughness at this time. The influence of the surface roughness on the frictional stress is more pronounced than that of the back tension.

\section{Conclusions}

According to the coupled use of rolling theory, fluid mechanics theory, friction and lubrication theory, and mechanical vibration theory, a mill system dynamic model that is based on the consideration of the roll gap unsteady lubrication process was constructed. This model integrated the rolling force model, the interfacial friction model, and the film constrained multi-factor coupling model of the interface that is constituted by work roll motion in the work interface. Through a critical analysis of the experimental results, the following theoretical understandings about the unsteady lubrication process were obtained. These findings hold promise for further experimental and theoretical investigation:

(1) In the process of metal rolling, the compressive stress in the deformation area is very sensitive to the surface roughness for case of relatively large back tension, and as the surface roughness increases, compressive stress in the roll gap increases. However, when the back tension reduces, the compressive stress becomes less sensitive to the surface roughness. 
(2) The surface roughness has a significant effect on the distribution of frictional stress in work roll. When there is a larger back tension, the compressive stress in the roll gap is lower, but the distribution of the frictional stresses is very sensitive to the surface roughness, and with an increase of surface roughness, the frictional stress in the roll gap also increases. The influence of surface roughness on frictional stress is more pronounced than that shown under back tension.

(3) The effects of some key parameters on the vertical self-excited vibration critical speed and amplitude of the mill were quantitatively analyzed. The results show that: the greater the viscosity of the rolling lubrication emulsion, the lower the vibration of the critical speed; the thinner the outlet thickness of the strip, the thicker the inlet thickness and the lower the critical vibration speed; the higher the surface roughness of the roll and strip, the higher the mill vibration critical speeds; the larger the radius of the roll, the higher the critical vibration speed; and the higher the rolling speed, the greater the amplitude.

\section{Acknowledgments}

This project is supported by the National Natural Science Foundation of China (51175133).

The authors would like to thank Dr. Colin Hadfield from the University of Wollongong for assisting in the English editing. 


\section{References}

[1] Kevin Dick, John G. Lenard. The effect of roll roughness and lubricant viscosity on the loads on the mill during cold rolling of steel strips. Journal of Materials Processing Technology 2005;168:16-24.

[2] Jian-liang SUN, Yan PENG, Hong-min LIU. Non-Linear Vibration and Stability of Moving Strip With Time-Dependent Tension in Rolling Process. Journal of Iron and Steel Research, International 2010;17:11-5.

[3] A. Świątoniowski, A. Bar. Parametrical excitement vibration in tandem mills-mathematical model and its analysis. Journal of Materials Processing Technology 2003;134:214-24.

[4] Xie HB, Jiang ZY, Yuen WYD. Analysis of friction and surface roughness effects on edge crack evolution of thin strip during cold rolling. Tribology International 2011;44:971-9.

[5] Cheng G. Investigation of interfacial behaviors between the strip and roll in strip rolling by finite element method. Tribology International 2005;38:413-22.

[6] Karam Kang, Chris Pelow, Lawrence Witham. Analysis of changes in 3D surface texture anisotropy ratio parameter and friction during sheet rolling campaigns. Wear 2008;264:434-8.

[7] Wilson WRD, Chang DF. Low speed mixed lubrication of bulk metal forming processes. ASME Journal of Tribology 1996;118:83-9.

[8] J.G. Beese. Lubrication of hot-strip-mill rolls . Wear 1973;23:203-8.

[9] A.G. Atkins. Hydrodynamic lubrication in cold rolling. International Journal of Mechanical Sciences 1974;16:1-19.

[10] M. Saniei,M. Salimi. Development of a mixed film lubrication model in cold rolling. Journal of Materials Processing Technology 2006;177:575-81.

[11] Stephany J, Ponthot P. Efficient algorithmic approach for mixed-lubrication in cold rolling. Journal of Materials Processing Technology 2004;153:307-13. 
[12] Jian Wen Choo, Andrew V. Olver, Hugh A. Spikes. The Influence of transverse roughness in thin film, mixed elastohydrodynamic lubrication. Tribology International 2007;40:220-32.

[13] Pei-Hua Hu, Kornel F. Ehmann. A dynamic model of the rolling process. Part II: Inhomogeneous model. International Journal of Machine Tools and Manufacture 2000;40:21-31.

[14] Pei-Hua Hu, Kornel F. Ehmann. A dynamic model of the rolling process. Part I: Homogeneous model. International Journal of Machine Tools and Manufacture 2000;40:1-19.

[15] Wilson WRD, Marsault N. Partial hydrodynamic lubrication with large fractional contact areas. Journal of Tribology 1998;120:16-20.

[16] Katyal P, Kumar P. Central film thickness formula for shear thinning lubricants in EHL point contacts under pure rolling. Tribology International 2012;48:113-21.

[17] Hibbeler RC. Mechanics of Materials. 4th Edition, London: Prentice Hall; 2000.

[18] Yun IS, Wilson WRD, Ehmann. Review of chatter studies in cold rolling. International Journal of Machine Tools \& Manufacture 1998;38:1499-530.

[19] Ginzburg VB. High-Quality Steel Rolling: Theory and Practice. New York: Marcel Dekker Inc.; 1993.

[20] Li H. A study on wear and surface roughness of work roll in cold rolling. Wollongong: University of Wollongong; 2008.

[21] Lagergren J. Friction evaluation in hot strip rolling by direct measurement in the roll gap of a model duo mill. Journal of Materials Processing Technology 1997;70:207-14.

[22] Christensen H. Stochastic models for hydrodynamic lubrication of rough surfaces. Proceedings of the Institution of Mechanical Engineers 1970;184:1013-22. 


\section{Figure Captions:}

Fig. 1. Geometry of roll bite

Fig. 2. Geometry of inlet zone

Fig. 3. Christensen surface roughness profile

Fig. 4. Free body diagram of a strip element

Fig. 5. Multi-factor coupling relationships of the interface

Fig. 6. Schematic illustration of the 2800 rolling mill vertical system model

Fig. 7. simulation block diagram

Fig. 8. Effect of rolling lubricant viscosity on vibration

Fig. 9. Effect of strip outlet thickness on vibration critical speed

Fig.10. Effect of strip inlet thickness on vibration critical speed

Fig.11. Effect of the roughness of strip and roll on vibration critical speed

Fig. 12. Effect of work roll radius on vibration critical speed

Fig. 13. Effect of rolling speed on vibration amplitude

Fig. 14. Pressure distributions for various reductions and surface roughness with sinusoidal back tension

Fig. 15. Friction stress distributions for various reductions and surface roughness with sinusoidal back tension 


\section{Table Captions:}

Table 1 Rolling mill system parameters and the parameters of emulsion performance. 


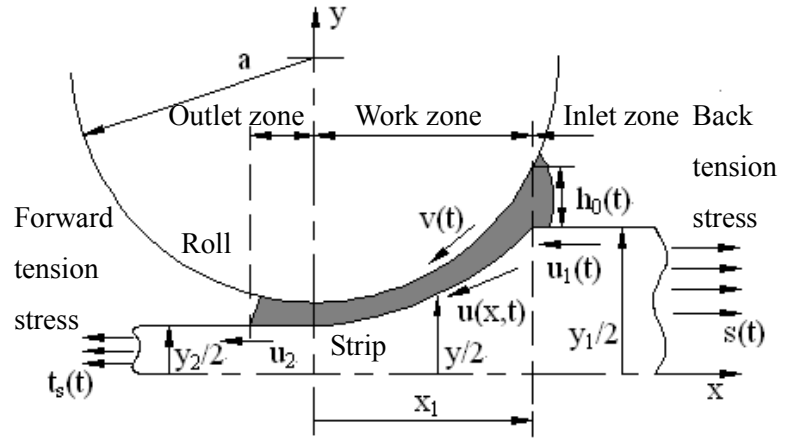

Fig. 1. Geometry of roll bite.

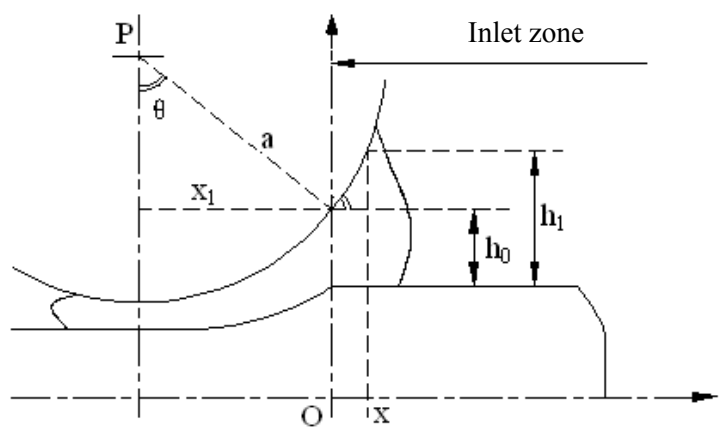

Fig. 2. Geometry of inlet zone. 


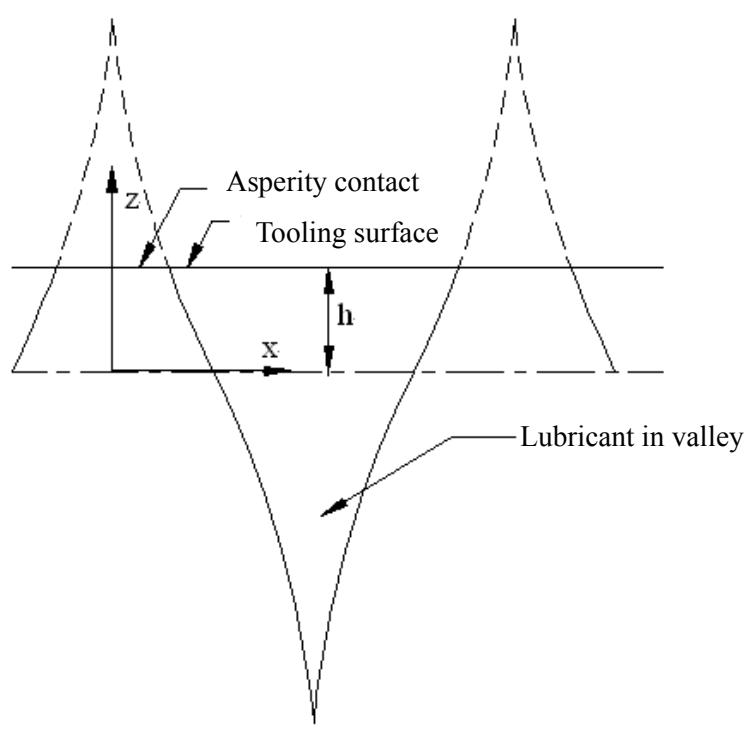

Fig. 3. Christensen surface roughness profile.

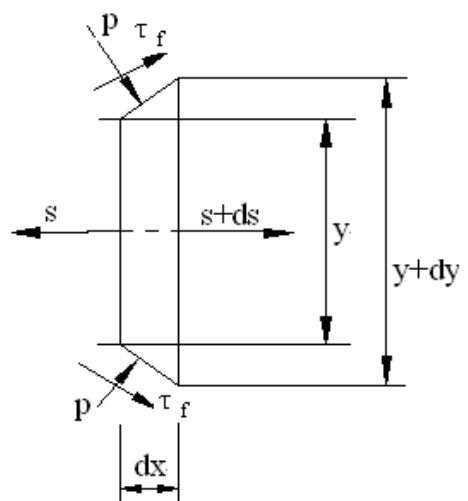

Fig. 4. Free body diagram of a strip element. 


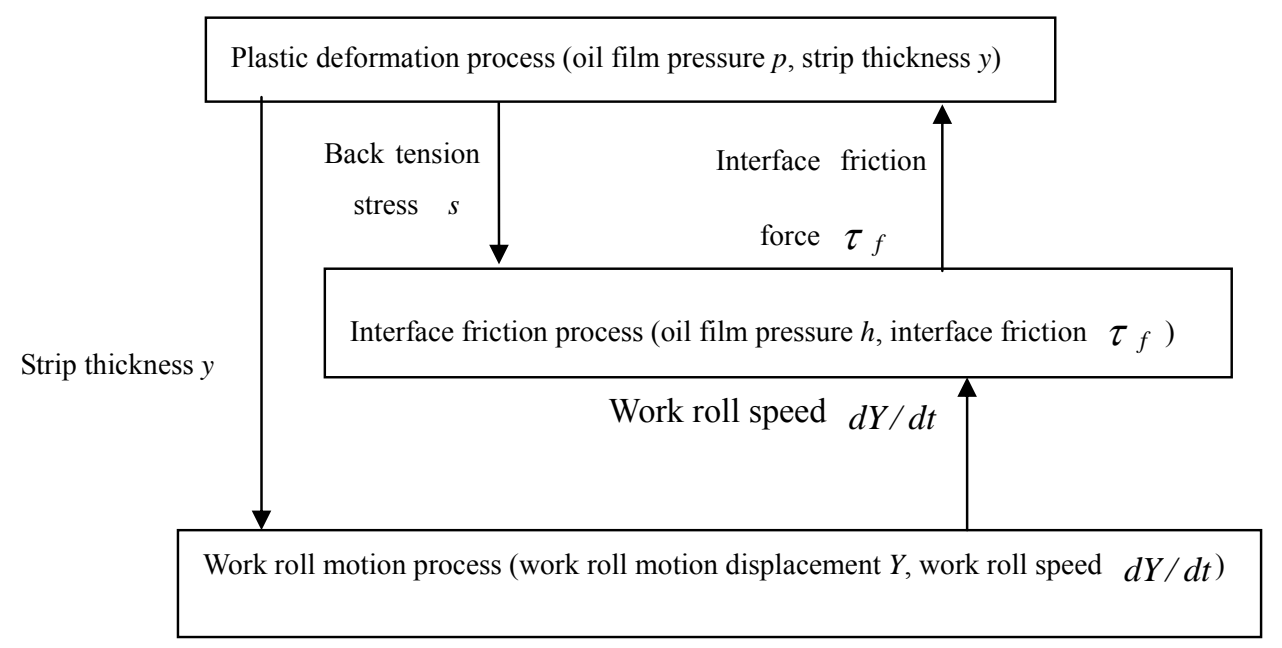

Fig. 5. Multi-factor coupling relationships of the interface. 


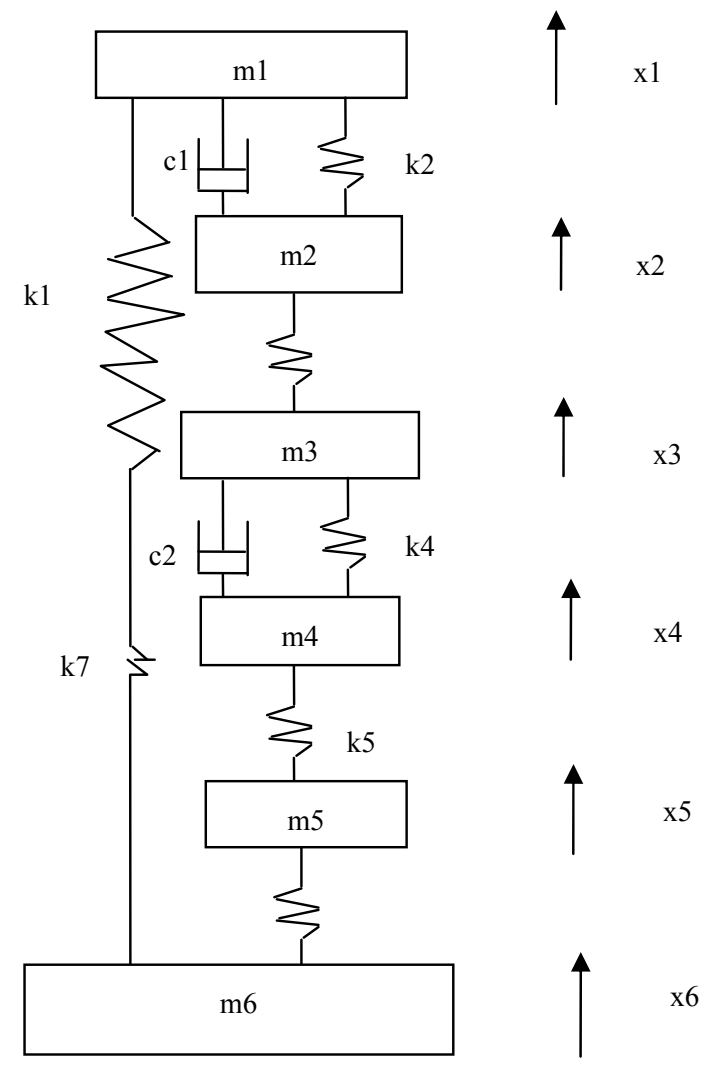

Fig. 6. Schematic illustration of the 2800 rolling mill vertical system model. 


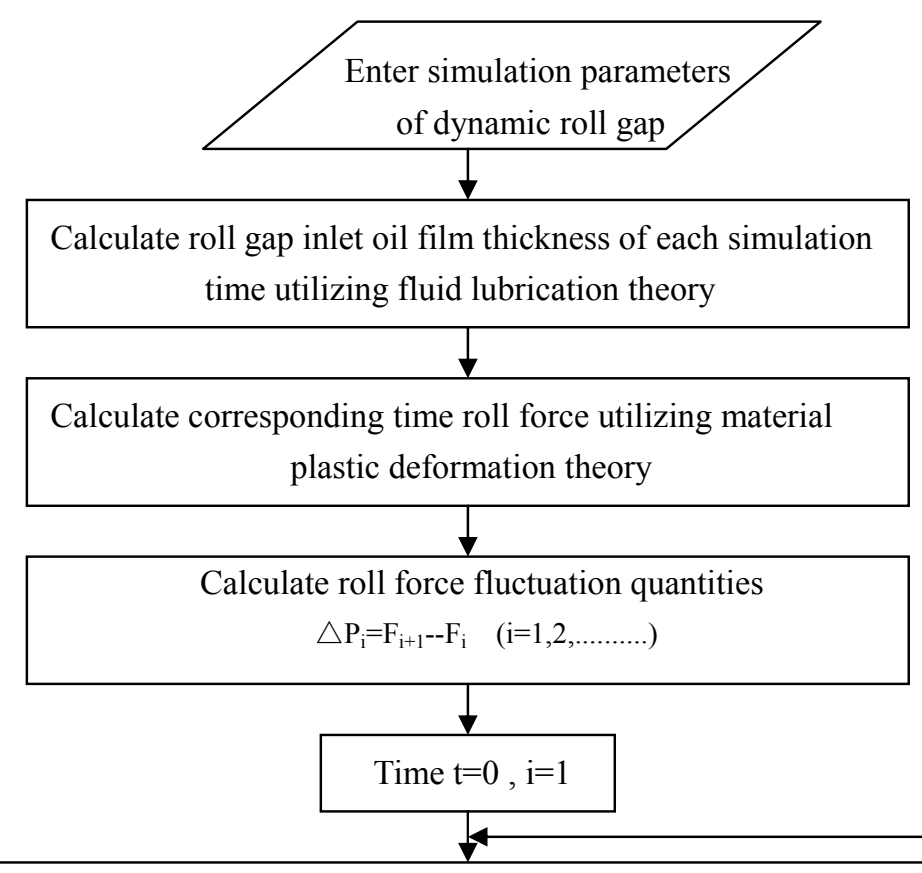

Solve vibration equation and calculate outlet strip thickness fluctuation quantities that caused by roll force fluctuation quantities using Newmark method

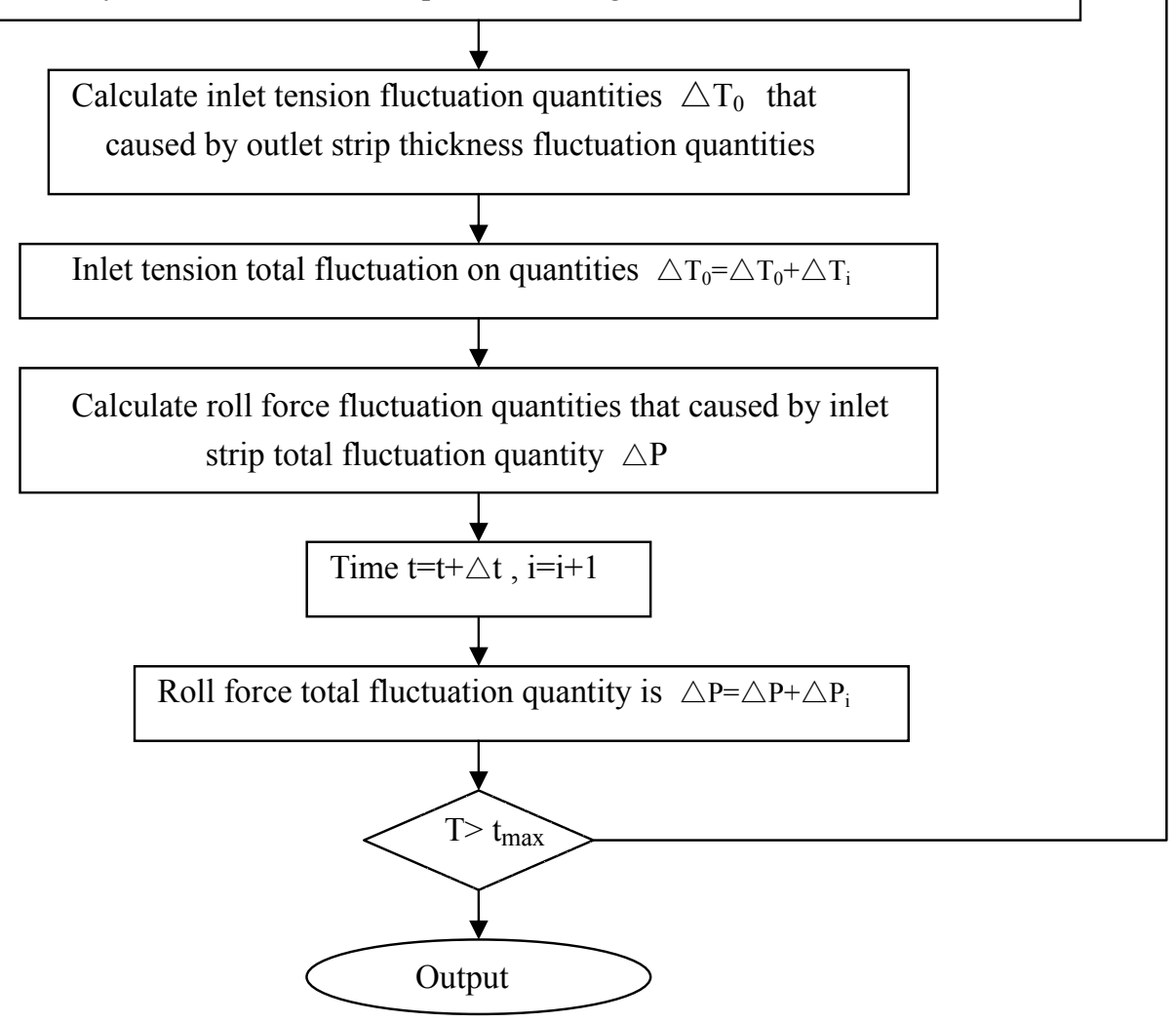

Fig. 7. simulation block diagram. 


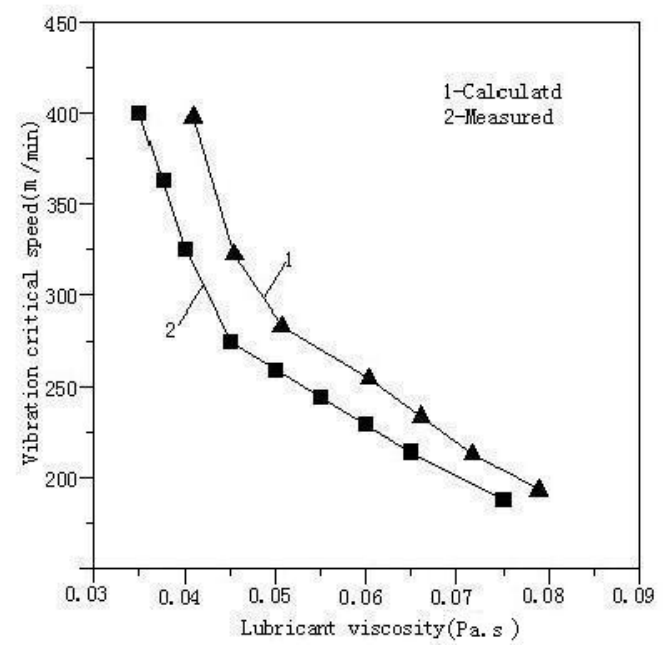

Fig. 8. Effect of rolling lubricant viscosity on vibration.

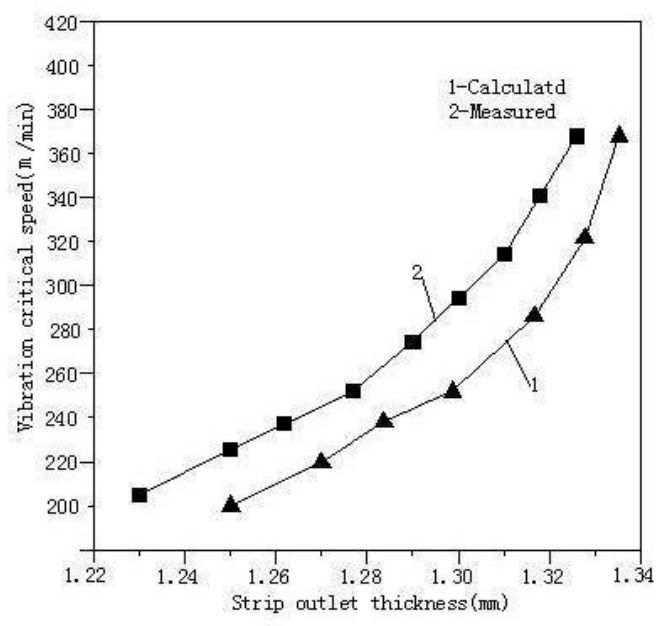

Fig. 9. Effect of strip outlet thickness on vibration critical speed. 


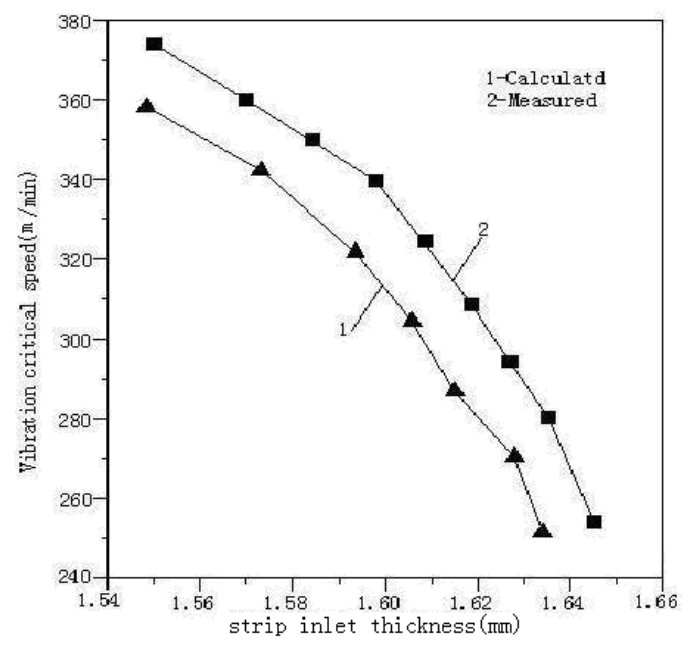

Fig.10. Effect of strip inlet thickness on vibration critical speed.

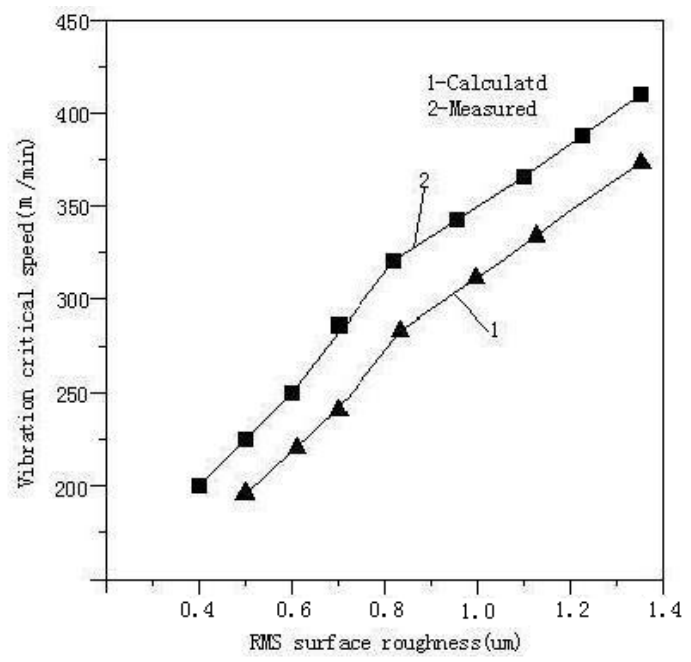

Fig.11. Effect of the roughness of strip and roll on vibration critical speed. 


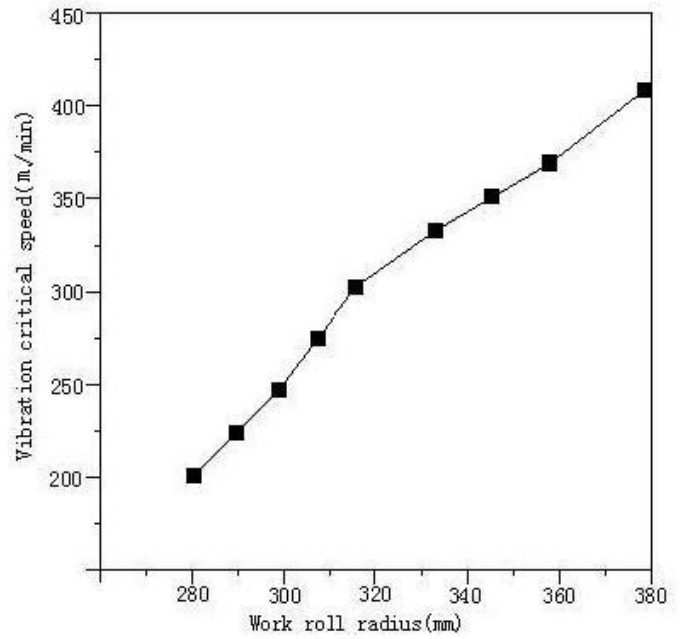

Fig. 12. Effect of work roll radius on vibration critical speed.

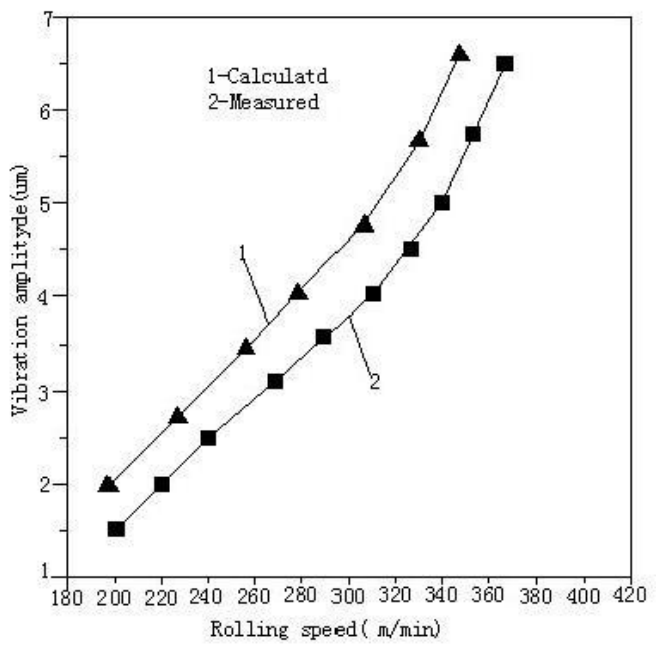

Fig. 13. Effect of rolling speed on vibration amplitude. 


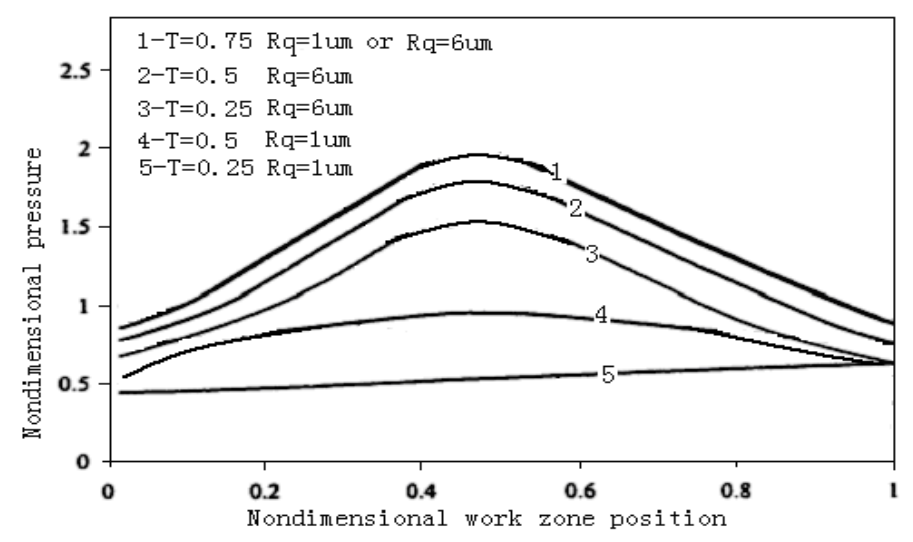

Fig. 14. Pressure distributions for various reductions and surface roughness with sinusoidal back tension.

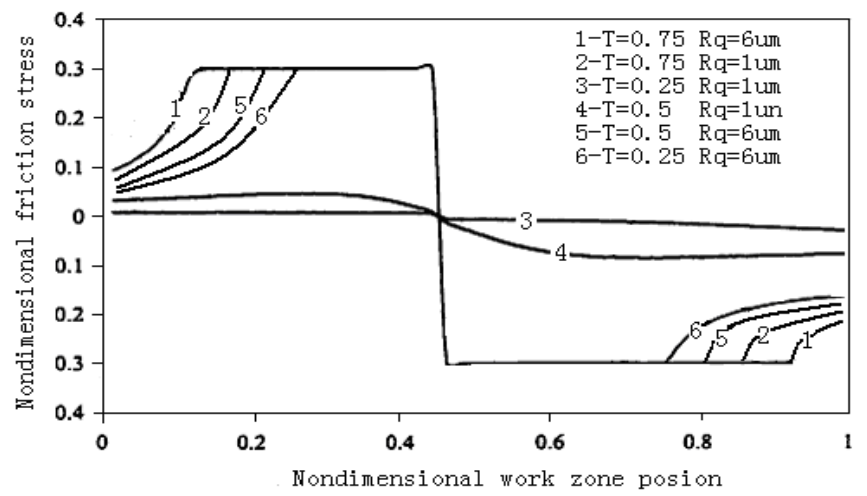

Fig. 15. Friction stress distributions for various reductions and surface roughness with sinusoidal back tension. 
Table 1 Rolling mill system parameters and the parameters of emulsion performance.

\begin{tabular}{ll}
\hline Parameters & Values \\
\hline Inlet strip thickness $y_{1}(\mathrm{~mm})$ & 1.6 \\
Material yield stress $\sigma\left(\mathrm{MP}_{\mathrm{a}}\right)$ & 380 \\
Back tension $s\left(\mathrm{MP}_{\mathrm{a}}\right)$ & 18 \\
Reduction $R$ & 0.15 \\
Roll radius $a(\mathrm{~mm})$ & 280 \\
Rolling speed $v(\mathrm{~m} / \mathrm{s})$ & 19 \\
Emulsion viscosity $\eta_{0}\left(\mathrm{P}_{\mathrm{a}} \mathrm{s}\right)$ & $5.5 \mathrm{e}-4$ \\
Pressure coefficient of viscosity & $\gamma\left(\mathrm{MP}_{\mathrm{a}}^{-1}\right)$
\end{tabular}

